\title{
Creativity as expression of subjectivity in old age
}

\author{
Maria Cristina Reis Amendoeira
}

Is a doctor (PhD) in Psychiatry, Psychoanalysis and Mental Health from the Institute of Psychiatry of Federal University of Rio de Janeiro - UFRJ. Master in Psychiatry, Psychoanalysis and Mental Health from UFRJ (2001). Physician at Instituto de Psiquiatria da Universidade Federal do Rio de Janeiro and researcher at the Labor and Mental Health Organization Program from 2006 to 2016.

Psychoanalyst affiliated to the Brazilian Society of Psychoanalysis in Rio de Janeiro (SBPRJ, IPA). Co-chair of Latin American of the Committee Psychoanalytic Perspectives on the Aging of Analysts and Patients, IPA - 2017.

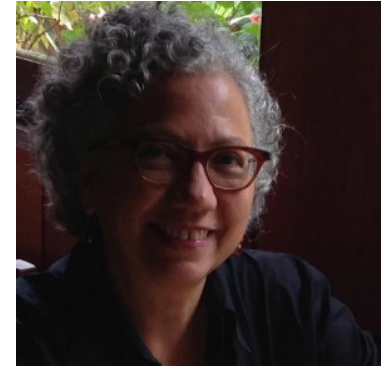

PhD Maria Cristina Reis Amendoeira
A $\mathrm{rt}$, aging, and subjectivity are related fields, since the creative process and its expression in culture are a concern for psychoanalysis. The aging process has recently become the focus of a number of psychoanalytic studies, including in terms of creativity as a resource for maintaining identity in the elderly.

Freud wrote that artistic activity, the consumption of art and the appreciation of natural and artistic beauty are among the acts that may make people happy.

Art deals with both the pleasure principle and the reality principle, which regulates our acceptance of social and cultural demands. Dreams and artistic creation also have something in common in that they seek to satisfy unconscious desires. Fantasizing is a sort of thought that does not depend on the presence of objects in the real world, and which is present in both children's play and adults' daydreaming.

Art brings about a reconciliation of these two principles, pleasure and reality, by way of a peculiar route. Artists are fundamentally people who, in refusing to fully accept the demand that they give up the satisfaction of their drives, instead give free rein to their erotic and ambitious desires in the realm of fantasy.

The psychoanalyst Fairbairn compared art to dreaming. The primary function of dreaming - to provide a means of expression for the dreamer's repressed needs -relieves the pressure exerted by those needs and reduces psychic tension. In dreams there is no motor activity, and reality is illusion. In the work of art, which is built by concrete activity, there is something present in external reality. Art provides a channel for the expression of aggressive fantasies and creates a means by which fantasies of reparation can be expressed.

For Segal, artistic activity is so deeply related to depressive anguish and reparative impulses that it might be considered an intention to "recover and recreate" the love object, "this lost world," both outside and inside oneself just as one does in successful grieving, accompanied by symbolization. These reparative processes are transmitted via formal beauty, representing the triumph of reparation over destruction. Segal casts unconscious fantasy as the source of creative art. From the very beginning of life, drives give rise to fantasy. Fantasizing is a defense against painful realities and evolves as one accumulates experience and learns from reality. Artistic creation, which was for a time considered the 
sublimation of sexual desires, has moved into a different stage, one in which the presence of destructive tendencies and narcissistic conflicts becomes relevant.

The expression of subjectivity occurs as an artist's sensibility is forged and emerges. For Freud, the measure of artists' abilities lay in the extent to which they could directly tap into the unconscious. Images, then, in their expressive potency, are a source of processes, affects, and significations. However, the artistic image is clearly superior to others in its inventiveness: it remains in the realm of discovery, bringing us closer to a field which is also that of psychoanalysis. It is a window to the soul that needs no other language.

Other psychoanalysts have contributed on this score, including Bion, who presents art as a transformative learning process, a need to seek out truth and freedom of thought.

But what places in their minds do creative artists plumb for the inspiration that can awaken such powerful emotions in all of us?

The field of art is a terrain of sensibility, and reveals itself to be richer in possibilities than the cognitive terrain. The limitations and need for change and adaptations that crop up as one ages may open up new poetic possibilities. This is the field in which limitations may be overcome or subverted. For example, we might take Matisse, who turned to collages and cut-outs near the end of his life in response to motor problems.

Many other artists are models for ways of processing losses, such as grieving, and processes of restoration and reparation in old age. Among them is Frida Kahlo, who, after a severe accident in her youth that would shape the rest of her life, wrote in her diary that her "painting carrie[d] with it the message of pain." Painting, she wrote, "completed my life."

The artist Louise Bourgeois, who works to process her traumas and express them in her art, speaks of reparation in terms of Kleinian psychoanalytic concepts. The basis for sublimation and creativity rests in the ability that each of us possesses to restore and recreate love objects, previously perceived as damaged, within ourselves. Alongside Freud, she affirms that artists can access the unconscious and symbolically express key psychical functions.

Artistic activity allows for transformation and growth, which we can consider a sort of psychical restoration. Art may be compared to psychotherapy in terms of ensuring mental sanity; in its relation to depressive anxieties and reparative impulses, it may be seen as an attempt by the subject to recover and recreate a love object both internally and externally. The sense of having one's inner world destroyed leads every artist to try to create and recreate something felt as new. Art, then, may be seen an attempt at resolution, a need to overcome depression and the fear of death, as Segal describes in her study on symbols.

Then, just as in grieving, art may be accompanied by symbolization. And these reparative processes come through in formal beauty, which stands for the triumph of reparation over destruction.

As we age, we face the real possibility of breaking bonds, and we may be drawn in by the death drive - a destructive, disconnecting force. It becomes a challenge to manage or keep up creative projects as we deal with losses of all sorts. Two paths emerge: isolation or the potential for creative processing.

At this stage of life, artistic creation may be seen as a therapeutic activity, a way for the subject to connect to his or her deepest emotions. The creative process bears a degree of frustration: the desire to attain beauty, balance, or the expression of a sentiment is powerful, but one can never predict which path will lead to that result. Reconstruction, recovering lost affections and primitive conflicts that may be revived and remobilized: all this lies in creativity. 
Art's therapeutic potential calls for the possibility of giving a form to profound emotions, transforming them and putting them on a different level. The human need to create and recreate reality finds in art a path to express subjectivity, and may bring emotional relief.

The transformations of assistance in the field of health and mental health care, with a renewed emphasis on rehabilitation, converge in practice with the conviction held by psychiatrist Nise da Silveira - a pioneer in valuing expressive activity, with her Museum of Images of the Unconscious - that a painting studio ought to be a space where we can express ourselves and relate freely, looking to accept and understand the other in their own specific language.

In the 1940s, Nise da Silveira inaugurated painting and sculpture workshops for her clients, most of them schizophrenics, in the Occupational Therapy sector at the National Psychiatric Center in the Rio de Janeiro neighborhood of Engenho de Dentro, where she worked from 1944 to 1975. Dissatisfied with the treatment methods of the time, she sought out new therapeutic approaches. Her patients worked regularly, which helped to hone their growing mastery of pictorial technique. Their paintings were created with no technical guidance, and without the aim of reproducing existing artwork. Almir Mavignier, their supervisor and an artist himself, strove to offer patients the best possible conditions for them to create freely, with no impediments.

Mário Pedrosa, an art critic at the newspaper Correio da Manhã, showed great interest in the matter. This visionary representation of the world, as he saw it, was not the sole province of the insane; it was present in every artist, in every sensitive being. The transfiguration of the world, at times fantastical and at other times more realistic, is the artist's craft. Artistic activity at its most powerful and profound manifests each person's talent in his or her affirmation of his or her existence; aesthetic pleasure releases the tensions of psychic life, thoughts, emotions and passions. Artistic creation restores subjects' dignity, inserting them not into a world of the old or the young, the healthy or the infirm, but into a social field in which creative work maintains all of us a part of the great adventure of humanity.

Dr. Silveira's life stands as an example of creativity, as many of her most important works - whether writings, audiovisual production, exhibitions, cultural events, or study groups - came about after she was forced to retire at age 70 . She kept on working and publishing until her death at age 94 .

Another paragon is psychoanalyst Marialzira Perestrello, who remained creative until just before her death in 2015. At age 91, in full possession of her intellectual powers, she studied the topic of creativity and aging.

The artists at the Museum of Images of the Unconscious were not immune to the passage of time. The painting studio became a space for free expression and active interaction with the other, acceptance and comprehension of the particular forms of language employed by each patient over the course of their lives. Among the artists who emerged from the wards and patios of the hospital and grew old at the National Psychiatric Center in Engenho de Dentro (now renamed the Nise da Silveira Municipal Institute of Mental Health Care), Emygdio de Barros, Carlos Pertuis, Fernando Diniz and Adelina Gomes are true examples of the persistence of creative ability in old age.

Mavignier says that, after years of not working with the studio, when he visited the Museum and was able to see the latest pieces from the clients he had worked with initially, he observed their technical refinement and artistic quality - this despite their age and the length of time they had spent in treatment.

Emygdio de Barros painted until age 92, and was considered by the poet Ferreira Gullar to be one of the rare geniuses in Brazilian painting. He was a Rio 
native, and his mother had some sort of mental disorder (she is remembered as always being shut up in her room, excluded from family life). Barros was a melancholy and shy child himself. But from early childhood, he demonstrated special manual abilities, building boxes and toys for himself. When working at the Navy Yard he was sent to take a technical course in France, where he remained for two years. Upon his return he took to wandering the streets and going into churches, where he would stand for hours on end, stock-still, staring straight ahead. Shortly thereafter, in 1924, he was taken to the Praia Vermelha Hospital and subsequently transferred to the hospital in Engenho de Dentro in 1944.

Despite the long years confined as a patient in adverse conditions, and without his having ever painted before, his work was of considerable artistic merit from the start, revealing extraordinary talent. He left a collection of some 3,300 pieces. When he was quite old and sick and had to be moved to a geriatric clinic, the team offered him material so that he could keep on painting. $\mathrm{He}$ refused, however, saying: "Just painting isn't what's important, what's important is having ideas to paint. Here at the clinic, I've got no ideas. I only have them at the Museum." The team made it possible for him to visit the studio at least twice a week, and that way he returned to painting. At age 92, he finished what would be his last piece. When Nisa da Silveira asked him what it meant, he pointed at the blue canvas and said: "It's the path to infinity."

Carlos Pertuis, also a Rio native, born to French grandparents and a French father, was the only son in a family with three sisters. Quite attached to his mother and physically and psychologically fragile, he was sensitive and had religious inclinations. He dropped out of school when his father died and began working at a shoe factory. The way that the sun hit the mirror in his room struck him as a cosmic vision, which he described as "God's planetarium." He was committed to the Praia Vermelha Hospital that same day, in 1939. In 1946, upon hearing of a patient who was keeping his drawings in shoeboxes in the ward, Almir Mavignier had him brought to the studio. Pertuis was not very verbal, and the plethora of neologisms that he used made it even more difficult to understand him.

He left behind a collection of 21,500 works. The last phase of his work, of remarkable aesthetic quality, was dubbed "The Long Voyage" by Mário Pedrosa. These pieces are considered the peak of his creative abilities. Near the end of his life he would trade his oil paint and brush for crayons; the result was a series of drawings with characters marching off into eternity.

Fernando Diniz, considered a poet of everyday life, was born in Aratu in the state of Bahia. Diniz was mixed-race and born to a poor family; he never met his father. At age four he came to Rio with his mother, where they lived in boardinghouses. Diniz went along with his mother, a seamstress, when she worked at rich families' houses. He dreamed of being an engineer. Though he was intelligent and a good student, he eventually dropped out. In 1944, when he walked into the sea fully clothed off Copacabana Beach, he was arrested and taken to the municipal insane asylum, later transferred to Engenho de Dentro in 1949. In the studio he kept his head low and barely spoke. Diniz explained the beauty of his paintings this way: "It's not me, it's the paint." His work encompasses everything from the figurative to the abstract, and its compositions include both simple forms and complex structures.

Diniz was an eternal apprentice. His passion for books made it so that he was constantly up to date with the latest events and scientific discoveries. The graphic result of all this is a kaleidoscope of images that are alternately sequential and superimposed, dynamic and colorful. From space to time, from the inorganic to the organic, from the geometric to the figurative and vice-versa, Fernando 
wove his universe. His interest in the movement of images ultimately led him to paint and draw a series inspired by cinema, in which he sought to represent time and space in the images. His animated short "Eight-Pointed Star" (supervised by Marcos Magalhães) would receive a slew of awards. As he put it: "I changed into the world of images, and my soul changed into something else. Images take our soul." At the Rio State University's Pedro Ernesto Hospital, even when quite ill, he collected refuse and recycled it into creative forms, putting together an extraordinary series that featured movement, among other things. He died at age 81 , leaving a collection of 30,000 pieces.

Adelina Gomes was the poor, shy daughter of farmworkers, born in the city of Campos in the state of Rio de Janeiro. She attended a technical school where she was trained in manual labor. At age 18 she fell in love; but her mother, to whom she was quite attached and to whom she submitted, rejected the potential groom. Gomes then grew increasingly withdrawn and was eventually committed to an institution in 1937, at age 21, after strangling her pet cat.

In an interview, Almir Mavignier recounted: "Aggressive and dangerous. That's the description they gave us of her, and they recommended that we not accept her at the studio. But I was interested in the dolls she was making at the hospital. I went to fetch her on a rainy day, and I sheltered her under an umbrella. That very normal, caring gesture must have contributed to winning her trust." Despite her negative, aggressive attitude, she was easily convinced to take up painting when she first began at the studio in 1946.

Gomes initially worked in clay, sculpting figures that are remarkably similar to images from the Neolithic period. Her subsequent paintings depict the metamorphoses of plants that she experienced in her hallucinations. She also made paper flowers. Adelina became a docile and warm person, always focused on her activities, who visited the Museum on a daily basis to paint. She died at age 68 on November $21^{\text {st }}, 1984$ after being attacked by another patient, never having left the hospital. She left a collection of 17,500 works.

Another artist who comes to mind when we think of art, the permanence of creativity, and madness is Arthur Bispo do Rosário, of the Colônia Juliano Moreira, who was diagnosed with paranoid schizophrenia and, between one institutionalization and another, spent nearly 50 years in the asylum. $\mathrm{He}$ produced over a thousand pieces with material he found at hand, such as utensils and sheets.

It may be said that in the visual production of these artists, we see no decline in creativity; in this they are similar to Chagal and Picasso. Images, in their expressive value, are a source of processes, affects, and significations. Art is necessary for humans to become able to grasp and change the world. In this sense, expressive activity may be a creative way out in the search for a new equilibrium in old age.

The need to reinvent reality is present in all of us. By way of creativity, we instinctively hunt after the feeling of being a subject who belongs to a given period and culture. Art is a way of communicating, and the aesthetic pleasure experienced by each of us may bring us closer to the poetic experience of the artist. This creative activity becomes a channel for emotional expression and communication for the aging artist. Art is more than a means for revealing truth; it represents in concrete and figurative form that which moves the human soul, and it is the very expression of that humanity.

Through the creation of images and sounds and the transformation of material into language, we become able to share our fears and delights with others. A relationship to artistic activity makes it possible for the elderly to 
incorporate new representations into their psychic lives, experience a new sense of identity and reconnect with internal founts of vitality.

When presented before the world, these pieces take on new meanings, as many as possible, as they establish a variety of connections to society and dialogue within the artistic realm. They will thus be open to other mediations and interpretations. Cézanne's advice on this score remains pertinent: to free the figure from any narrative whatsoever and let it become a path for sensation. And the emotion it awakens in us brings us closer to a new happening.

The crises we undergo activate the potential of creative work and our ability to process events, transforming these moments of crisis into life lessons. Aging is yet another step in the development of the psyche, and a creative attitude makes it possible to evaluate and reevaluate life experience, now seen from a fresh perspective. Creativity and creation are the result of psychic work that, along with the work of mourning, may lead to new realizations. That way we may truly experience the passage of time creatively. 